\title{
BMJ Global Health Global burden of maternal bereavement: indicators of the cumulative prevalence of child loss
}

\author{
Emily Smith-Greenaway, ${ }^{1}$ Diego Alburez-Gutierrez, ${ }^{2}$ Jenny Trinitapoli, ${ }^{3}$ \\ Emilio Zagheni ${ }^{2}$
}

To cite: Smith-Greenaway E, Alburez-Gutierrez D, Trinitapoli J, et al. Global burden of maternal bereavement: indicators of the cumulative prevalence of child loss. BMJ Global Health 2021;6:e004837. doi:10.1136/ bmjgh-2020-004837

Handling editor Sanni Yaya

- Additional material is published online only. To view, please visit the journal online (http://dx.doi.org/10.1136/ bmjgh-2020-004837).

Received 22 December 2020 Revised 1 March 2021 Accepted 7 March 202
Check for updates

(c) Author(s) (or their employer(s)) 2021. Re-use permitted under CC BY-NC. No commercial re-use. See rights and permissions. Published by BMJ.

${ }^{1}$ Sociology \& Spatial Sciences, University of Southern California, Los Angeles, California, USA ${ }^{2}$ Max Planck Institute for Demographic Research, Rostock, Germany

${ }^{3}$ Sociology, University of Chicago, Chicago, Illinois, USA

Correspondence to Dr Emily Smith-Greenaway; smithgre@usc.edu

\section{ABSTRACT}

Background We provide country-level estimates of the cumulative prevalence of mothers bereaved by a child's death in 170 countries and territories.

Methods We generate indicators of the cumulative prevalence of mothers who have had an infant, underfive-year-old or any-age child ever die by using publicly available survey data in 89 countries and an indirect approach that combines formal kinship models and lifetable methods in an additional 81 countries. We label these measures the maternal cumulative prevalence of infant mortality (mIM), under-five mortality (mU5M) and offspring mortality $(\mathrm{mOM})$ and generate prevalence estimates for 20-44-year-old and 45-49-year-old mothers.

Results In several Asian and European countries, the mIM and $\mathrm{mU} 5 \mathrm{M}$ are below 10 per 1000 mothers yet exceed 200 per 1000 mothers in several Middle Eastern and African countries. Global inequality in mothers' experience of child Ioss is enormous: mothers in high-mortality-burden African countries are more than 100 times more likely to have had a child die than mothers in low-mortality-burden Asian and European countries. In more than 20 African countries, the m0M exceeds 500 per 1000 mothers, meaning that it is typical for a surviving 45-49-year-old mother to be bereaved.

Discussion The study reveals enormous global disparities in mothers' experience of child loss and identifies a need for more research on the downstream mental and physical health risks associated with parental bereavement.

\section{BACKGROUND}

Infant and child mortality rates have declined worldwide over the last 50 years, signifying notable progress for children and their parents. Reductions in annualised rates of infant and child mortality, however, cannot reasonably proxy parents' cumulative experiences of child loss, a phenomenon we refer to as parental bereavement. A child's death can have serious and long-lasting consequences for parents, ${ }^{2-4}$ but the population prevalence of bereaved parents has only been estimated for a select group of countries in sub-Saharan Africa. ${ }^{5}$ From those estimates, as recently as 2015 , over one-third of

\section{Key questions}

What is already known?

- In sub-Saharan African countries, maternal indicators of the child mortality burden show that-even as infant and child mortality rates decline-having experienced a child's death remains a common maternal experience.

- Child death is known to adversely affect mothers lives, yet we lack a systematic, global analysis of the maternal prevalence of child loss.

\section{What are the new findings?}

- Our results offer estimates of the maternal cumulative prevalence of infant, under-five and all offspring mortality for 20-44-year-old and 45-49-year-old mothers in 170 countries, providing a new view of the burden of premature death across the globe.

- Global inequality in mothers' experience of child death is enormous: mothers in select African countries are more than 100 times more likely to have had a child die than mothers in select Asian or European countries; the most dramatic inequalities are between younger mothers (ages 20-34).

\section{What do the new findings imply?}

- Quantifying maternal experiences of child loss offers a new perspective of the population burden of child death, reveals how disparate maternal conditions are worldwide and attests to the need for additional individual-level research on the consequences of child loss for families.

mothers in sub-Saharan Africa had experienced a child death. ${ }^{5}$ It remains unclear whether such high levels of maternal bereavement characterise other low-income and middle-income countries and how this burden compares to high-income countries.

In this article, we provide the first population-level estimates of the prevalence of bereaved mothers in 170 countries. We generate three indicators of the cumulative prevalence of mothers who have had an infant, under-five-year-old or any-age child die. We label these indicators: the maternal 
cumulative prevalence of infant mortality (mIM), underfive mortality (mU5M) and offspring mortality (mOM).$^{5}$ To achieve global coverage, we generate these indicators through a combination of direct estimation, using publicly available survey data and an indirect-estimation strategy using publicly available age-specific fertility and mortality schedules. ${ }^{6}$

Population-level measures of maternal bereavement summarise how infant, child and adolescent mortality conditions accumulate, forming a corresponding shadow population of bereaved parents deserving of public health attention. Global inequalities in the burden of family bereavement reflect disparate health environments and may also compound disadvantage by leaving parents vulnerable to the grief, trauma and other adverse outcomes associated with bereavement. ${ }^{7-11}$ A child's death can have profound and lasting influence on parents' well-being, including their mental health, physical health and longevity. ${ }^{2-4} 12-20$ The health consequences associated with bereavement are especially severe for mothers, and the adverse effects of grief can persist for years-even decades. ${ }^{16}$ Child loss can also adversely impact other aspects of parents' lives, including the health and stability of their marital union. ${ }^{318}$ The guilt, blame, stigma, stress and relationship strain associated with child loss have been documented across diverse cultural contexts, including in settings where child loss is a tragically common and perhaps, even, an anticipated aspect of motherhood. ${ }^{21-25}$ By demonstrating the size and distribution of child loss across the globe, these metrics render visible an inequity that has been overlooked in the global health literature.

Our study also clarifies that a population's parental bereavement burden cannot be inferred from current mortality indicators because it is patterned by both past and present mortality and fertility conditions. In terms of mortality: a legacy of higher child and adolescent mortality years earlier will linger in the birth histories of older mothers, contributing to higher lifetime experiences of bereavement. Past and present death rates dictate not just the likelihood of losing a child but also how many bereaved mothers have survived versus how many died prematurely, thereby erasing their experience of child loss from the contemporary record. The degree to which child deaths are dispersed across families versus concentrated among a disadvantaged few further shapes the total societal reach of these experiences. On fertility: a parents' cumulative risk of experiencing a child die is determined by exposure, specifically the number of children she has. ${ }^{26}$ Thus, this worldwide portrait of maternal bereavement offers a fundamentally new perspective on the global-health landscape.

\section{METHODS}

\section{Data sources}

Survey-based estimates of maternal bereavement

We generate indicators of the maternal cumulative prevalence of child death directly using microdata from nationally representative surveys that collect full birth histories from female respondents. ${ }^{27}$ To expand country coverage beyond what is achievable with publicly available survey data, we introduce an indirect approach that uses formal demographic methods to estimate the prevalence of bereaved mothers in a population.

Our direct estimation strategy makes use of three data sources. For 56 countries (see online supplemental table S1), we leverage data from the Demographic and Health Surveys (DHS) programme. DHS data come from nationally representative household surveys that feature large sample sizes (usually between 5000 and 30000 households) (see https://dhsprogram.com/). DHS interviewers collect detailed information from various household members, including birth history data from women ages 15-49. To offer recent estimates of child loss, we restrict our analysis to surveys collected between 2010 and 2018 .

In 32 additional countries where recent DHS data are not available (see online supplemental table $\mathrm{S} 1$ ), we make use of data from the Multiple Indicator Cluster Surveys (MICS). MICS is an international household survey programme developed and supported by UNICEF (see https://mics.unicef.org/). MICS interviewers similarly collect data from various household members, including birth history data from women ages $15-49$. Note that MICS data does not collect information on children's age at the time of death; thus, we only use these data to calculate estimates of all offspring mortality. Again, we leverage surveys collected between 2010 and 2018.

For the USA, we make use of the National Survey of Family Growth (NSFG) (2013-2017). NSFG is a nationally representative survey of ever-married women in the civilian, non-institutionalised population of the USA (see https://www.cdc.gov/nchs/nsfg/index.htm). NSFG interviews are conducted in-person and feature birth history calendars. Because the NSFG included ever-married women 45 years and older in only one survey round (and contain a small sample for this age group), we use these data to generate direct estimates for 20-44-year-old mothers and rely on our indirect approach (explained below) for older mothers. Note that unlike the DHS and MICS, the NSFG sample is comprised only of ever-married women. The exclusion of never-married mothers from NSFG data is a limitation for our direct estimates. For the USA, there is evidence that births to unmarried women are at elevated risk of infant death, compared with births to married women. ${ }^{28}$ This means that our indicators based on NSFG for the USA may underestimate the prevalence of maternal bereavement. However, as shown in online supplemental figure S1, the NSFG-based estimates are largely consistent with those generated using our indirect estimation strategy, which does not suffer from this sampling restriction, indicating that the size of potential underestimation is likely small.

In each survey, we restrict the analytic sample to women who had at least one live birth (i.e., the women ever exposed to the risk of a child's death). Among these mothers, we calculate the prevalence estimates using 
data collected through their birth histories, specifically information on the vital status of each child ever born and, for those deceased, the age at death. Given data constraints, we do not include pregnancy loss in our estimates; our measures focus on deaths that followed a live birth. Online supplemental table S1 lists all countries, data sources, survey years and sample sizes.

To estimate the mIM, we sum the number of mothers who had a child die before age one, divide this by the number who ever had a live birth, and express this per 1000 mothers. To estimate the mU5M, we do the same for mothers who ever had a child die before age five. Finally, the mOM indexes all experiences of child death, regardless of the child's age at the time of death.

In the main results, we calculate the mIM and mU5M indicators separately for mothers of reproductive age (20-44-year-old mothers), and those completing their reproductive years (45-49-year-old mothers). Because a relatively small share of 20-44-year-old mothers had children above age five, due to right-censoring and the associated concerns about selection, we calculate the $\mathrm{mOM}$ for 45-49-year-old mothers only. We appropriately weight all survey-based estimates of the $\mathrm{mIM}, \mathrm{mU} 5 \mathrm{M}$ and $\mathrm{mOM}$.

To check whether the wide age-band of 20-44years old is concealing important variation among mothers at the youngest and oldest ends of the age spectrum, we present $\mathrm{mIM}$ and $\mathrm{mU} 5 \mathrm{M}$ estimates for 5-year age groups (15-19, 20-24, 25-29, 30-34, 35-39, 40-44) in supplementary analyses (see online supplemental table S2). Note that we exclude adolescent mothers (15-19years old) from the main summary measures but include them in online supplemental table S2. Because births to 15-19-year-old mothers are subject to a distinct set of social and physiological conditions known to elevate the risk of adverse outcomes ${ }^{29}$ as with the estimates for the oldest mothers, we report these separately.

\section{Kin-cohort-based estimates of maternal bereavement}

Not all countries regularly collect data containing detailed birth histories. We supplement the survey-based estimates using an indirect, kin-cohort approach. ${ }^{6}$ We use this approach to generate the mIM, mU5M and mOM indicators for an additional 81 countries and territories with populations of 1 million or more, for which we lack appropriate survey data; this results in our study covering 170 countries and territories (98\% of the world's population). ${ }^{30}$

The kin-cohort estimation method (described in detail in online supplemental appendix) relies on demographic rates and requires cohort mortality and fertility schedules, which we approximate from publicly available demographic rate data from the 2019 Revision of the United Nations World Population Prospects (UNWPP) (see https://population.un.org/wpp/). We make use of UNWPP demographic estimates for calendar years 19501955 through 2015-2020. We obtain single-calendar-year estimates using a combination of spline and linear interpolation techniques.
To generate period estimates of the maternal cumulative prevalence of infant, under-five and offspring death that are directly synonymous as those that we generate with survey data, we extend classic approaches from mathematical demography, designed for populations with constant demographic rates, ${ }^{31} 32$ to non-stable populations with changing demographic rates over time, and combine them with life-table methods.

Specifically, we generate the mIM, mU5M and mOM in four steps, which we elaborate on further in online supplemental appendix. First, we begin by using countryspecific mortality life tables and discrete kinship equations to calculate the age-specific probability that an average woman will experience the death of an infant, under-five or any-age child. ${ }^{33}$ This estimate does not account for women's survivorship to specific ages; thus, second, we create a life table ${ }^{34}$ with a survivorship column that determines the fraction of women in each cohort who survive to each age. By considering the age-specific probability of losing a child and the proportion of women in each birth cohort who survive to each age, we can solve for the proportion of surviving women in each birth cohort who have ever lost an infant, under-five or any-age child by a specific age.

The third step is to tailor the estimates of child death to pertain to the proportion of surviving mothers, not all surviving women, which includes those that have never had a live birth. To do so, we use a similar lifetable approach to calculate the proportion of women who have had at least one birth at each age using agespecific fertility rates. We treat fertility as a 'hazard rate'; we approximate the number of women that have never had a child, given a set of age-specific fertility rates, and then calculate the inverse of that quantity: the proportion of women who have given birth to at least one child, by age. We then multiply the proportion of women who have lost a child before age one/age five/any age by the proportion of women who have had at least one live birth in order to estimate, for a given cohort, the proportion of mothers who have ever lost a child who was an infant/ younger than age five/any age.

The fourth and final step is to convert these cohortspecific estimates to period ones so that they can be interpreted as the direct survey estimates of the mIM, mU5M and mOM. Here, we set the estimates to refer to calendar year 2016 - the modal year of survey coverage. We then restrict the samples to the relevant age groups to estimate the mIM, mU5M and mOM for 20-44-year-old mothers and 45-49-year-old mothers specifically.

Online supplemental table S1 denotes our estimation strategy for each point estimate (results generated using the kin-cohort approach are italicised).

\section{Robustness check: the comparability of indirect and direct estimates}

Although we prioritise the survey-based estimates and only rely on the indirectly generated kin-cohort estimates for countries or territories where survey data are unavailable, 
in a supplementary analysis, we compare estimates using both strategies. We rely heavily on the kin-cohort approach in all regions except sub-Saharan Africa. We are fortunate to have such high survey coverage in this region, especially given that the UNWPP data for many African countries rely on model life tables, which violate some of the key assumptions of the kin-cohort approach. Thus, in this supplementary analysis, we focus on the 45 non-African countries and territories with survey data to compare the estimates with those generated using the kin-cohort approach. As shown in online supplemental figure S1, we found high correspondence: the two estimation strategies produced values that differed, on average, by less than $1 \%$ for 20-44-year-old mothers (mIM and mU5M) and between $4 \%$ and $6 \%$ for 45-49-year-old mothers (mIM, mU5M, mOM).

When there are discrepancies between the survey-based prevalence estimates and those calculated using the kincohort approach, the latter strategy tends to yield slightly higher estimates. We suspect that the discrepancy is driven by the fact that the indirect kin-cohort approach cannot account for the well-known phenomenon of householdlevel mortality clustering. ${ }^{35}{ }^{36}$ That is, because the kin-cohort approach averages deaths across all mothers and does not recognise that some mothers experience repeated losses in a short-time period, it can overestimate the population prevalence of bereaved mothers.

\section{Patient and public involvement}

We use secondary data for the analysis. Therefore, no patient consent was needed.

\section{RESULTS}

\section{Maternal burden of infant mortality}

Figure 1 maps the mIM for 20-44-year-old mothers, offering a global portrait of the prevalence of young mothers who have experienced an infant death. In seven countries and territories, fewer than 5 per 1000 of young mothers have ever lost an infant (Hong Kong, Japan, Singapore, Finland, Iceland, Spain, Sweden; see online supplemental table S1). In 34 countries, however, the mIM exceeds 150 per 1000 young mothers, meaning that 30 times as many mothers have experienced an infant death than in these low-mortality-burden settings. And in as many as 16 of these countries-all located in subSaharan Africa and the Middle East-more than 200 per 1000 mothers have lost an infant (Afghanistan, Burkina Faso, Central African Republic, Chad, Democratic Republic of the Congo, Ethiopia, Equatorial Guinea, Guinea, Guinea-Bissau, Liberia, Mozambique, Niger, Nigeria, Sierra Leone, Somalia and South Sudan; see online supplemental table S1).

Figure 1 reveals a profound inequity in maternal experiences across different countries, and importantly, it does so in a way that infant mortality rates do not. For example, the global range of mIM values for 20-44-year-old mothers stretches from the low of 2.8 per 1000 mothers in Hong Kong to 303.3 per 1000 mothers in Sierra Leone; this means that young mothers in Sierra Leone are 108 times more likely to have experienced a child die than their counterparts in Hong Kong. Viewed in proportional terms, this difference in young mothers' likelihood of having endured an infant child's death exceeds the already large discrepancy in the populations' infant mortality rates (81 vs 1 infant deaths per 1000 live births) ${ }^{37}$

This wide-age band could conceal differences in maternal age-specific rates in the mIM; to address this, online supplemental table S2 presents the mIM indicators for 5-year age groups of mothers, including adolescent mothers. The results show that the mIM values generally follow an age-gradient; however, the height of this gradient varies across regions. In Asia and the Pacific and

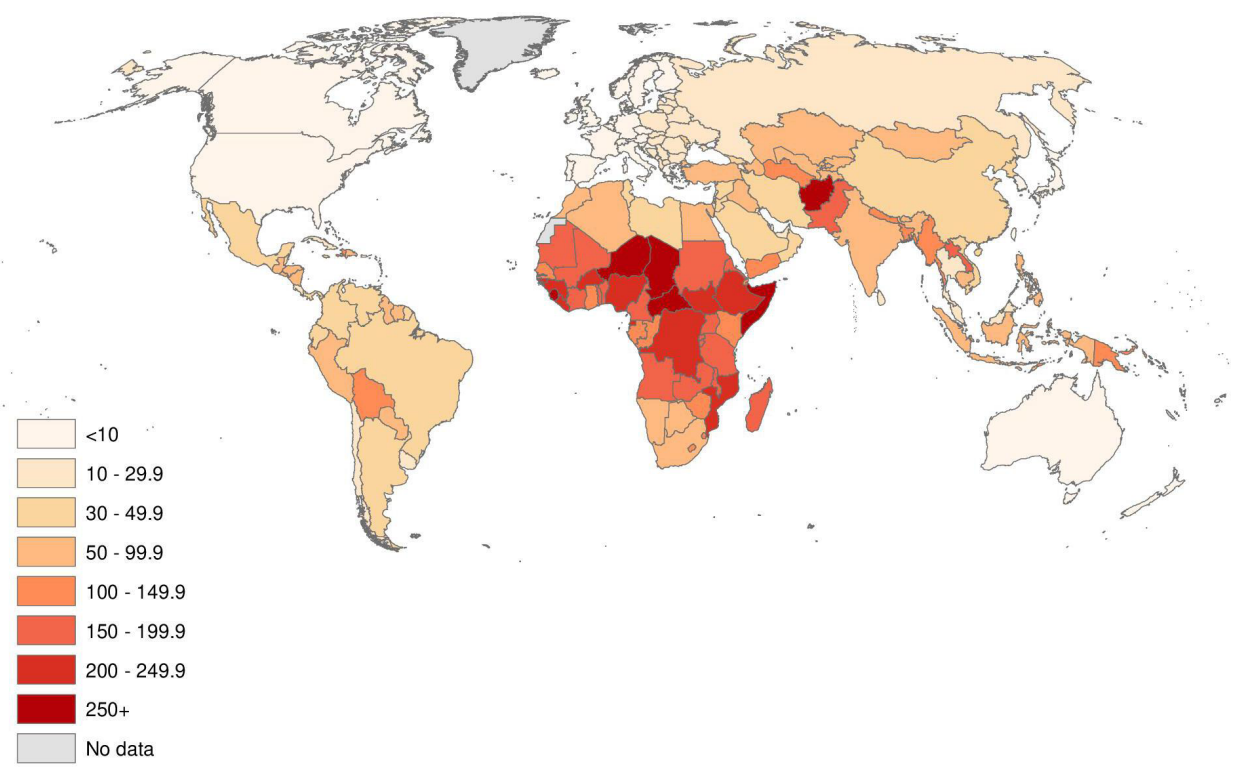

Figure 1 Maternal cumulative prevalence of infant mortality for mothers age $20-44$. See online supplemental table S1 for list of estimates and data sources. 


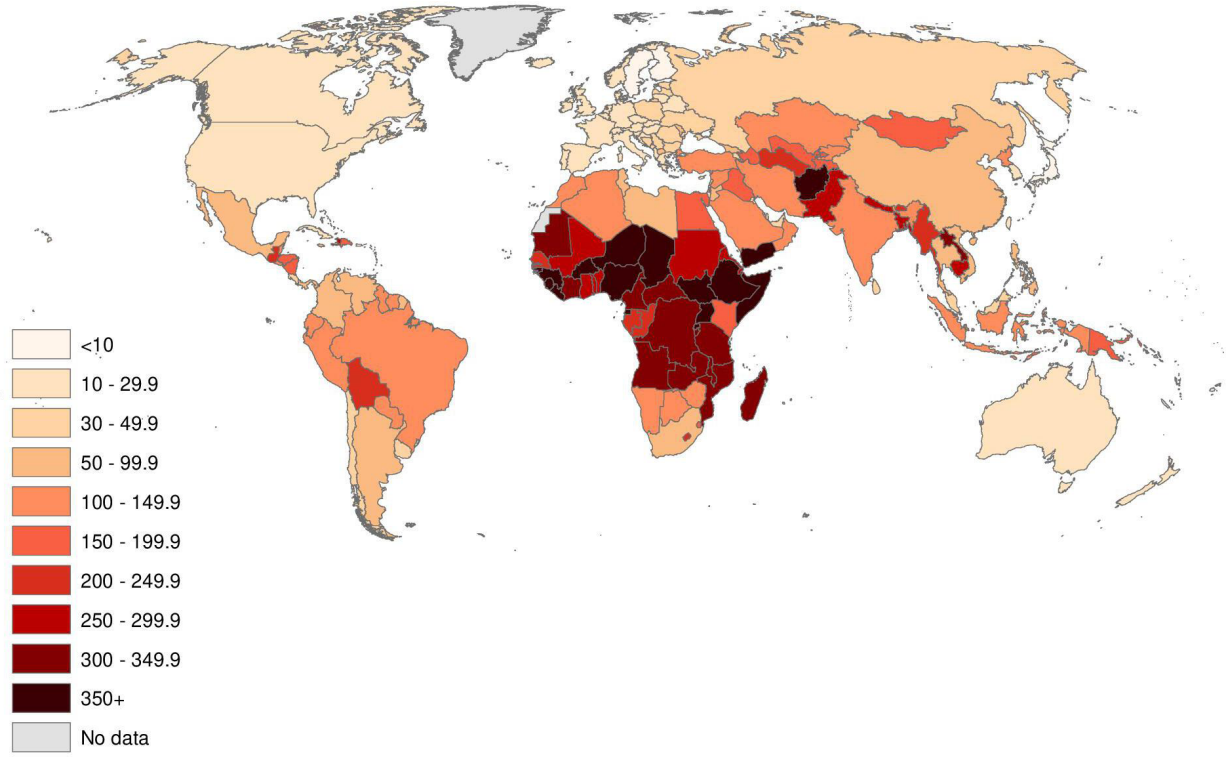

Eastern Europe, 40-44-year-old mothers are four to five times more likely to have experienced an infant die than 20-24-year-old mothers. Conversely, in Western Europe, 40-44-year-old mothers are just twice as likely to have experienced an infant die than 20-24-year-old mothers. Although motherhood is exceedingly rare among adolescents overall, in 40 countries, more than 50 per 1000 15-19-year-old mothers have experienced an infant die.

Given that mortality declines of historic proportions have swept the globe in recent decades, it is plausible to anticipate that the global range of values for the maternal burden of bereavement will be largest for mothers in their late 30s and 40s; however, we find no evidence this is the case. Between-country differences in child loss are the largest among 20-24-year-old mothers (mIM of 1.2 in Albania vs 167.0 in Sierra Leone), 25-29-year-old mothers (mIM of 1.9 in Hong Kong vs 239.7 in Sierra Leone) and 30-34-year-old mothers (mIM of 2.4 in Hong Kong vs in 337.0 in Guinea).

Figure 2 presents the mIM estimates for 45-49-year-old mothers. As expected, the cumulative prevalence of infant mortality for this older age group is higher than the estimates documented for young mothers; this is due to a combination of their having entered motherhood under higher mortality conditions and having had more children. Again, these estimates show large discrepancies in maternal experiences of infant death across the globe. In Hong Kong, Finland, Japan, Singapore and Sweden, fewer than 10 per 1000 of older mothers have lost an infant. In 53 countries across the Middle East and subSaharan Africa, however, over 200 per 1000 older mothers have. Older mothers in Liberia (mIM of 465.3 per 1000 mothers) are 69 times more likely to have experienced an infant die than older mothers in Hong Kong, the country with the lowest recorded mIM for older mothers (6.7 per 1000 mothers). Interestingly, the range in level of infant bereavement for older mothers is narrower than that for younger mothers. This may be, at least in part, due to the legacy of higher infant mortality rates worldwide. It could also be a function of excess mortality among large proportions of bereaved mothers in the highest mortality populations.

\section{Maternal burden of under-five mortality}

Figure 3 maps the mU5M for younger mothers, summarising the prevalence of 20-44-year-old mothers who have experienced a child die between birth and age five. The list of low mU5M countries and territories closely mirrors that for the mIM estimates. In Hong Kong, Japan and Singapore, fewer than 5 per 1000 young mothers have experienced a child die before age five; in more than a dozen countries across the Middle East and West and Central Africa, however, more than 300 per 1000 mothers have lost a child (Afghanistan, Burkina Faso, Cameroon, Central African Republic, Chad, Equatorial Guinea, Guinea, Guinea-Bissau, Liberia, Niger, Nigeria, Sierra Leone, Somalia and South Sudan; see online supplemental table S1). Globally, the mU5M for 20-44-year-old mothers ranges from 3.9 per 1000 mothers in Hong Kong to 437.2 per 1000 in Niger. As with the mIM, the inequality in mothers' experiences of under-five mortality far exceeds both current and historical differences in under-five mortality rates: mothers in Niger are 112 times more likely to have endured a child's death than mothers in Hong Kong, though the under-five mortality rate in the former is only 43 times higher than the latter (two under-five deaths per 1000 in Hong Kong vs 85 per 1000 in Niger).

Before turning to estimates for older mothers, in online supplemental table S2 we present the mU5M values for 5-year-birth cohorts of mothers, including adolescent mothers. Like the mIM, the mU5M age-gradient 


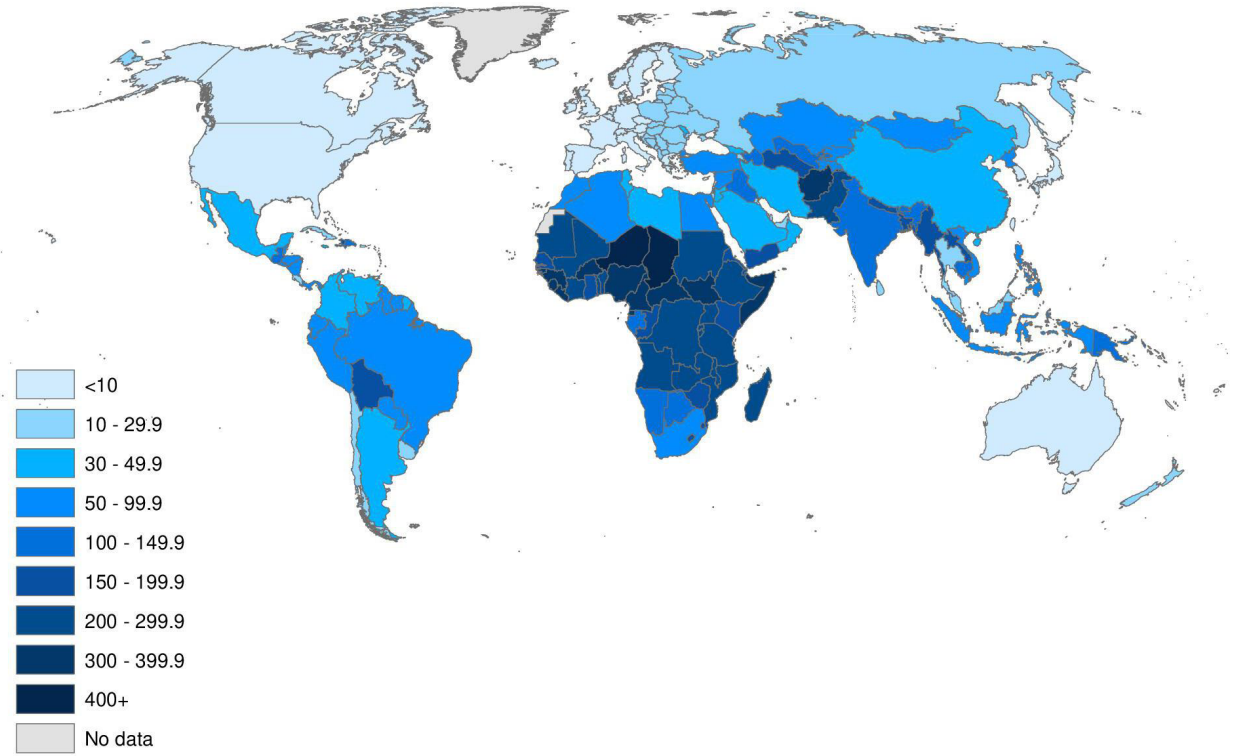

Figure 3 Maternal cumulative prevalence of under-five mortality for mothers age 20-44. See online supplemental table S1 for list of estimates and data sources.

is variable across regions, with the steepest gradients in Africa, Asia and the Pacific and Eastern Europe, presumably due to older women's cohorts having experienced far higher mortality and fertility conditions relative to their younger counterparts. Western European countries follow a more gradual age-gradient. Because distinct cohorts of mothers having experienced similar mortality and fertility conditions in this region, the results likely reflect true age differences associated with mothers' differential exposure to under-five loss. These findings also show that even for young women who very recently entered motherhood, there is wide gap in their experiences of under-five loss. For instance, 25-29-year-old mothers in Niger are 142 times more likely to have had an under-five-year-old child die than same-age mothers in Hong Kong.

Turning to the mU5M estimates for older mothers, figure 4 reinforces the insights derived by the previous three metrics: in very low-mortality-burden countries, fewer than 30 per 1000 older mothers have ever lost an under-five child, and in Hong Kong and Singapore, the estimates are less than 10 per 1000 . In these settings, a mother experiencing a young child's death is highly unusual. Yet nearly 100 countries, which accounted for $75 \%$ of the world's population in 2016, have mU5M levels among older mothers that are 10 times higher. In total, the estimates range from 8.8 (Hong Kong) to 705.7 per 1000 mothers (Niger), demonstrating

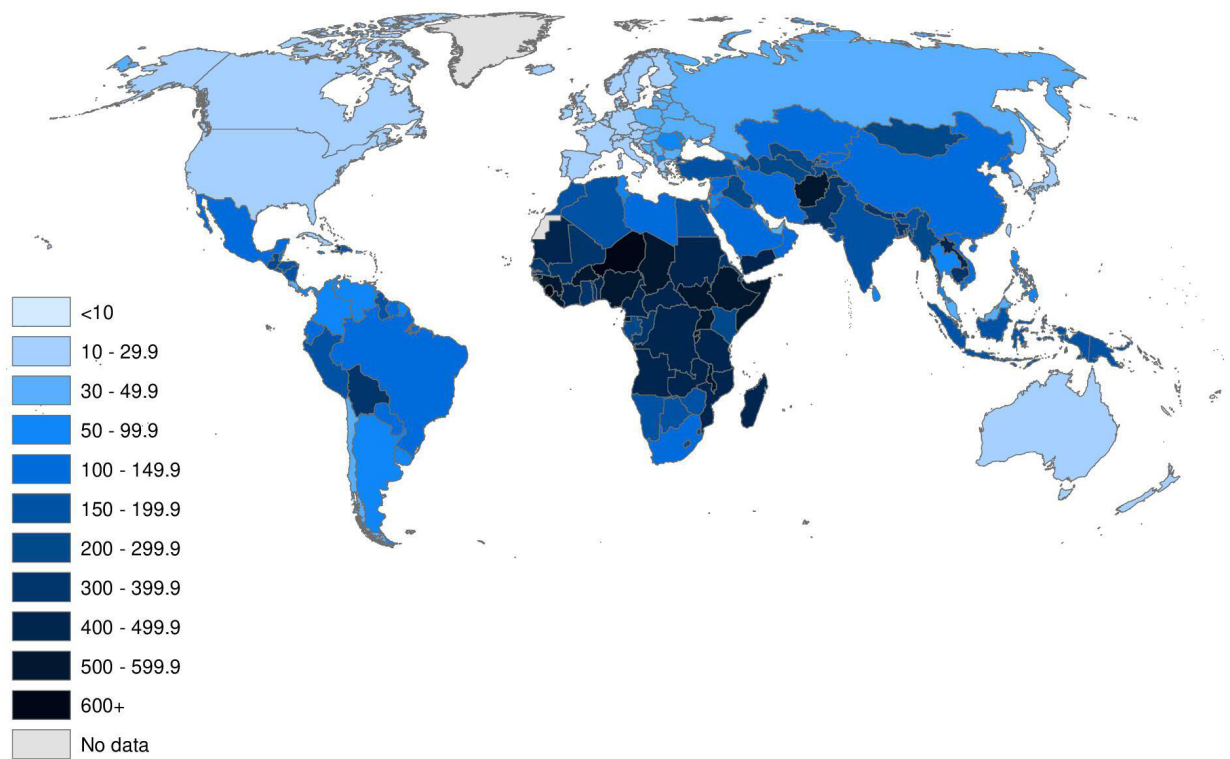

Figure 4 Maternal cumulative prevalence of under-five mortality for mothers age 45-49. See online supplemental table S1 for list of estimates and data sources. 


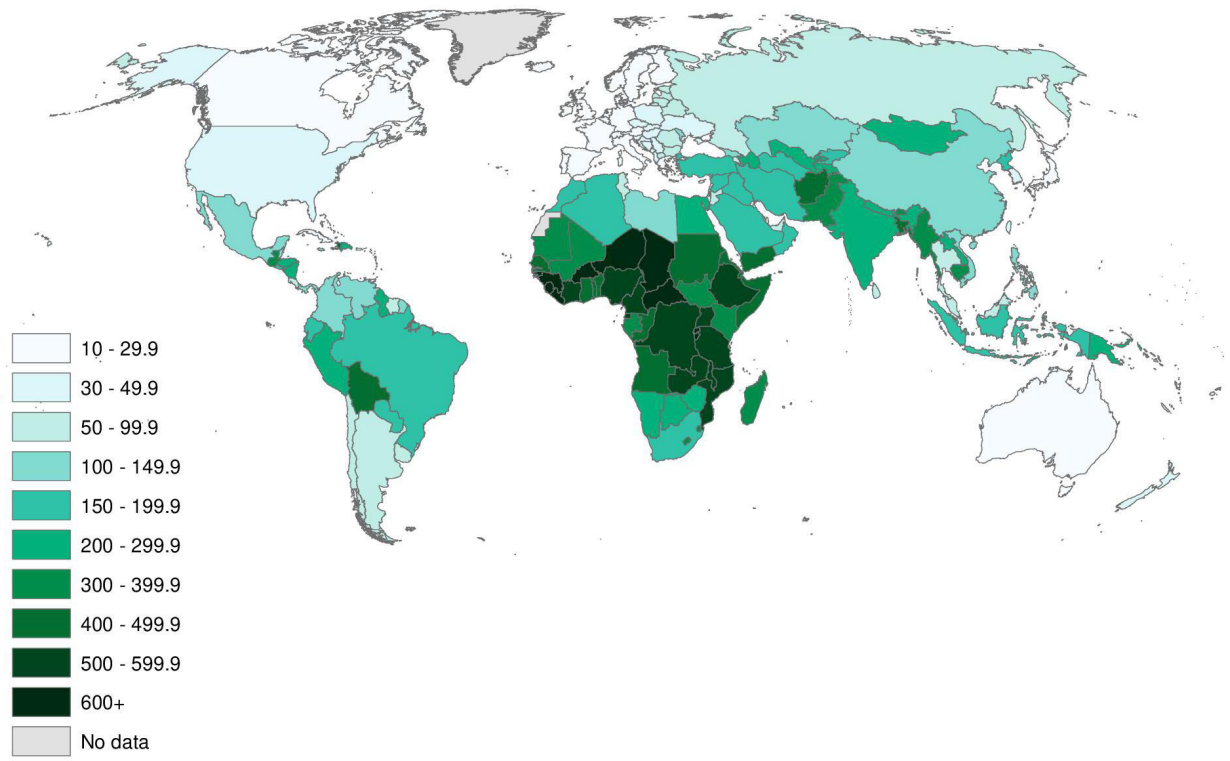

tremendous inequity in maternal experiences across the globe.

\section{Maternal burden of offspring mortality}

The global-health community emphasises the importance of measuring and monitoring mortality among children under age five; however, parents' risk of losing a child persists beyond a child's fifth birthday. To understand the total burden of child loss, regardless of the child's age at the time of death, figure 5 displays the $\mathrm{mOM}$, which enumerates all offspring mortality among 45-49-year-old mothers. As expected, the global patterning of the $\mathrm{mOM}$ values closely aligns with those of the mIM and mU5M: where many surviving mothers have had an infant or under-five-year-old child die, many have lost adolescent and young adult children also. The prevailing pattern across high-income Asian and European countries is that fewer than 30 per 1000 mothers have ever lost a child. In 50 countries in Africa, Latin America, the Middle East and Southeast Asia, however, the mOM levels are at least 10 times higher: in these countries, more than one-third of surviving mothers have ever lost a child. In 21 countries-all within sub-Saharan Africa-more than one-half of surviving older mothers have had a child die. The mOM ranges from a low of 12.1 per 1000 mothers (Hong Kong) to a high of 792.6 per 1000 mothers (Niger).

\section{DISCUSSION}

This study formalises a way to measure the populationlevel burden of maternal bereavement. In doing so, we identified gross inequities in the burden of child loss across the globe-inequities that exceed what we already know from child-centred measures of mortality. Even as infant and mortality conditions improve worldwide, mothers in some low-income and middle-income countries are more than 10 times as likely to have had a child die than their counterparts in high-income countries. Across much of sub-Saharan Africa, mothers are more than 100 times more likely to have experienced a child die than mothers in the world's wealthy, low-mortalityburden enclaves.

Although the global patterning of the mIM and mU5M is closely correlated with existing child mortality metrics, we assert the value of systematically estimating and studying the maternal burden of child loss as its own, unique phenomenon. For example, among the 20 countries with the world's lowest under-five mortality rates between 2015 and $2020,{ }^{37}$ four do not feature among the 20 countries with the lowest mU5Ms among young mothers. Similarly, four of the top 20 countries with the highest mU5Ms among young mothers do not rank among the countries with the highest under-five mortality rates. This point is made further evident when we compare the mU5M values to achievement of Goal 3.2 of the sustainable development goals (SDG): an under-five mortality rate lower than 25 per 1000 births. $^{38}$ Some countries and territories that have achieved the SDG goals for under-five mortality (per UNWPP data for 2015-2020) have higher levels of maternal bereavement than countries that have yet to achieve these goals (eg, Peru and Honduras). Conversely, some countries that have not met the SDG goal have relatively low levels of maternal bereavement (eg, Philippines and Trinidad and Tobago). These inversions underscore the value of explicitly quantifying the burden of child loss with parent-centred measures.

Beyond offering a new metric to understand betweencountry differences in parents' burden of premature mortality, the results also quantify the sheer weight of this burden across low-income and middle-income countries where most of the world's population reside. Overlaying the prevalence estimates with research on parental 
bereavement highlights yet another meta-inequality: the world regions in which child loss is concentrated are less commonly the focus of empirical research dedicated to understanding the consequences of this experience. The few studies that have examined the cost of child loss for mothers in high-bereavement contexts show that health, physical safety, social standing and mental well-being are all compromised in the aftermath of a child's death; this confirms the salience of bereavement for efforts to understand and improve women's health in these highmortality settings. ${ }^{21} 242539$

The high burden of child loss in these contexts may also perpetuate intergenerational health disadvantages. Parents are not the only family members affected. Sibling loss is a form of adversity for young people. ${ }^{40-42}$ A sibling's death may affect child development through its consequences for their parents or as a direct result of the severed sibling relationship. Despite how common sibling bereavement is across the globe, ${ }^{43}$ it is rarely studied as a significant life course event in low-income and middleincome country settings. Indeed, the WHO's widely used Adverse Childhood Experiences-International Questionnaire asks only of parental death, ${ }^{44}$ paying no mind to the adversity that stems from sibling loss. The burden of parental bereavement mandates ongoing measurement and analysis of its consequences for both parents-and their surviving children-alike.

While emphasising the need for more research on the consequences of family bereavement, the results clarify the often-large share of families that would benefit from programmatic efforts to support those grieving. ${ }^{39}$ Even as paediatric palliative care expands worldwide, ${ }^{39}$ in high-mortality contexts, in particular, mothers report that their grief is often unrecognised by healthcare providers and that their needs for timely and culturally appropriate psychological support go unmet. ${ }^{45}{ }^{46}$ Comparative research suggests that the death of a child is a universally consequential experience, ${ }^{47}$ yet like in all matters of global health, ${ }^{48}$ locally designed, implemented and assessed bereavement programmes are warranted, given the significant cultural differences in lived grief experiences. $^{49} 50$ Trained community members successfully provide bereavement counselling to orphans ${ }^{51}$; mutualsupport groups are effective in similar contexts for orphaned populations. ${ }^{52}$ Programmes like these could be redesigned and expanded to provide equivalent kinds of trauma-informed support to bereaved parents.

The study findings also underscore the need for universal bereavement leave policies worldwide. Bereavement leave entitlements are rare, but their merits are being discussed more seriously in the face of the current, heavy burden of COVID-19 mortality. ${ }^{53}$ By shifting from an annual to a life course perspective of bereavement, our study findings rescale understandings of the share of the population cumulatively affected by the lack of accommodations when losses occur. Additional advocacy for basic bereavement-related services and support through global or national strategies and programmes is needed to address this neglected policy issue.

Our work to quantify the share of a population affected by bereavement also informs efforts to conceptualise, measure and address the global mental health burden. ${ }^{55-57} \mathrm{~A}$ growing literature on global mental health has documented high levels of depression in many lower income countries, particularly among women..$^{58}$ By drawing attention to parental bereavement-a wellknown risk factor for depression-mOM measures remind researchers that, at any given time, a large share of the adult population may present with depressive symptoms due to a normal grief response to their own child's death or deaths of other children in their community, family or extended social network. When measuring mental health in a global framework, some of what gets documented as poor mental health could, in fact, be a healthy human response to loss. ${ }^{59}$ Failure to differentiate between acute grief that produces depression-like symptoms and clinical depression could distort understanding of global mental health.

At the same time, 'disordered grief' is prevalent after losing a child ${ }^{60}$ poorly understood in population-based samples, and almost never studied in high-mortality contexts. Where it has been studied, complicated grief or prolonged grief disorder (PGD) - severe and acute grief that impairs function in important domains of everyday life-may affect as much as $7 \%$ of the bereaved population. ${ }^{61}$ Applying that estimate to societies in which 600 out of 1000 mothers have lost a child, the prevalence of PGD tied to parental bereavement alone could affect more than 40 per 1000 mothers. PGD was recently recognised by the WHO, but is still scarce in the medical literature and almost never combined with mortality research. ${ }^{62}$ The potential for high levels of PGD, and its possible misdiagnosis as depression ${ }^{59}$ warrants more careful measurement in efforts to study mental health globally. Screening for PGD is critical for clinicians who diagnose and treat patients, and for researchers profiling the global burden of disease.

Our study provides a comprehensive and systematic way to catalogue the global burden of maternal bereavement in contemporary and historical populations, but the indicators are susceptible to measurement limitations. First, the birth histories collected by the DHS and MICS have limitations that could bias our estimates. Even as these surveys are the foundation of global studies of child mortality ${ }^{1}$ and are widely held as the gold standard ${ }^{63} 64$ for mortality research generally, they are limited by sources of error that point in the direction of under-reporting. ${ }^{65}$ Recent validation research suggests that a significant percentage of neonatal deaths experienced by women 15-49 years old were left out of birth histories due to complete omission or the misclassification of deaths as stillbirths. ${ }^{65}$ This kind of under-reporting of neonatal deaths may downwardly bias our measures of infant loss. Other types of errors are more concerning for 
estimating post-neonatal deaths, also in the direction of under-reporting. Instances of false positives due to misclassification or date reporting could artificially inflate the mIM or mU5M; however, recent research suggests such error is far less common. ${ }^{65}$ Overall, the survey-based mIM and mU5M estimates are most certainly conservative.

A second limitation is that the maternal cumulative prevalence indicators are affected by multiple sources of censoring. Not every birth reported on by mothers has been fully observed through their first or fifth birthday, so some of these 'non-bereaved' mothers (especially 20-44 years old) will experience an infant or child under-five die later in life. Additionally, given that the oldest mothers are only $45-49$ years old, and the children of these mothers are generally younger than 30 years; thus, the cumulative indicator of alloffspring mortality pertains specifically to children who died between infancy and earlier adulthood. The mOM estimates are also censored and should not be mistaken for lifetime estimates of a mother's risk of child loss. Indeed, our estimates omit deceased mothers who may have experienced higher levels of offspring mortality than mothers still alive. Survivor bias will also lead to conservative estimates, especially in sub-Saharan Africa, a region with some of the world's highest maternal mortality rates. ${ }^{66} 67$ Moreover, because HIV/AIDS causes joint maternal-child deaths, our estimates may be especially conservative in countries that recently experienced severe HIV epidemics. ${ }^{68}$

Our intentionally parsimonious approach has advantages-notably the ease by which these snapshot indicators can be estimated and scaled to new aggregates. The survey-based estimates are simple tabulations and, in the case of the $\mathrm{mOM}$, require only three data points: the woman's age, whether she has ever had a life birth and whether any children are deceased. To calculate the mIM and mU5M, the only additional data needed is the age of the child at the time of death. Even when survey data are unavailable, researchers can apply the kin-cohort method offered here to UNWPP dataan open source available for every country worldwide-or any published demographic rates, including those at the subnational level. Incorporating these measures into international efforts to track mortality conditions could help to increase recognition and mobilise resources to address issues associated with bereavement.

The indicators offered in this paper are centred around a maternal perspective; we have not generated analogous paternal cumulative prevalence estimates of infant, under-five and all-offspring mortality. This is a consequence of data limitations, not a value judgement. Surveys with detailed birth history data from men are extremely rare, a reality that must shift to address the paucity of empirical research on paternal bereavement. A small literature on the implications of child loss for fathers suggests that they often suffer silently ${ }^{69}$; fathers experience anxiety and depression and sometimes become emotionally or physically abusive in the wake of a child's death. ${ }^{25} 70$ An analogous study of the paternal bereavement burden would, in all likelihood, produce a substantively similar account of what we have documented here for mothers. But the sheer scale of maternal bereavement indicates a need for more data on parents' experiences of lossincluding men's-across diverse global contexts. Beyond prevalence estimates, this would include their experiences of, and reactions to, child death.

Keeping these limitations in mind, the mIM, mU5M and mOM estimates convey how epidemiological inequalities accumulate in surviving mothers' lives. Although we have introduced these measures at the country-level, the general approach is highly flexible and can also document the uneven burden of child loss across social groups within countries. Evidence from sub-Saharan Africa shows large and persistent disparities in mothers' burden of child loss across economic strata and subnational regions. ${ }^{5}$ Similarly, research in the USA increasingly acknowledges that the burden of family bereavement is disproportionately concentrated among Black Americans relative to White Americans-reflecting and, arguably, contributing to the reproduction of disadvantage. ${ }^{8}$ Future research should move beyond cross-national comparisons to examine within-country inequalities, as these constitute the bulk of all global health inequality. ${ }^{71}$ Efforts to understand the bereavement burden will elaborate a vital dimension of a population's mortality regime-one that merits the attention and resources of health scholars and practitioners.

Twitter Emily Smith-Greenaway @smithgreenaway, Diego Alburez-Gutierrez @d_alburez, Jenny Trinitapoli @JTrinitapoli and Emilio Zagheni @ezagheni

Contributors ES-G produced the empirical results using survey data and DA-G conducted the indirect demographic analysis. ES-G drafted the initial manuscript. All four authors contributed to revising and editing the article.

Funding The authors have not declared a specific grant for this research from any funding agency in the public, commercial or not-for-profit sectors.

Map disclaimer The depiction of boundaries on this map does not imply the expression of any opinion whatsoever on the part of BMJ (or any member of its group) concerning the legal status of any country, territory, jurisdiction or area or of its authorities. This map is provided without any warranty of any kind, either express or implied.

Competing interests None declared.

Patient consent for publication Not required.

Ethics approval University of Southern California Institutional Review Board (UP-20-00015).

Provenance and peer review Not commissioned; externally peer reviewed.

Data availability statement All data used in this study are publicly available. DHS data are available at https://dhsprogram.com/. MICS data are available at https:// mics.unicef.org/. NSFG data are available at https://www.cdc.gov/nchs/nsfg/index. htm. Replication files are posted at Harvard Dataverse, https://doi.org/10.7910/ DVN/UVBVZ7 (27)

Supplemental material This content has been supplied by the author(s). It has not been vetted by BMJ Publishing Group Limited (BMJ) and may not have been peer-reviewed. Any opinions or recommendations discussed are solely those 
of the author(s) and are not endorsed by BMJ. BMJ disclaims all liability and responsibility arising from any reliance placed on the content. Where the content includes any translated material, BMJ does not warrant the accuracy and reliability of the translations (including but not limited to local regulations, clinical guidelines, terminology, drug names and drug dosages), and is not responsible for any error and/or omissions arising from translation and adaptation or otherwise.

Open access This is an open access article distributed in accordance with the Creative Commons Attribution Non Commercial (CC BY-NC 4.0) license, which permits others to distribute, remix, adapt, build upon this work non-commercially, and license their derivative works on different terms, provided the original work is properly cited, appropriate credit is given, any changes made indicated, and the use is non-commercial. See: http://creativecommons.org/licenses/by-nc/4.0/.

\section{REFERENCES}

1 Liu L, Oza S, Hogan D, et al. Global, regional, and national causes of child mortality in 2000-13, with projections to inform post-2015 priorities: an updated systematic analysis. The Lancet 2015;385:430-40.

2 Stroebe S, H. A. W, Stroebe W. Health consequences of bereavement: a review. Lancet Infect Dis 2007;370:1960-73.

3 Stroebe M, Schut $\mathrm{H}$. To continue or relinquish bonds: a review of consequences for the bereaved. Death Stud 2005;29:477-94.

4 Rogers CH, Floyd FJ, Seltzer MM, et al. Long-Term effects of the death of a child on parents' adjustment in midlife. J Fam Psychol 2008;22:203-11.

5 Smith-Greenaway E, Trinitapoli J. Maternal cumulative prevalence measures of child mortality show heavy burden in sub-Saharan Africa. Proc Natl Acad Sci U S A 2020;117:4027-33.

6 Alburez-Gutierrez D, Kolk M, Zagheni E. Forthcoming. "Women's experience of child death over the life course: A global demographic perspective." Demography.

7 Fletcher J, Mailick M, Song J, et al. A sibling death in the family: common and consequential. Demography 2013;50:803-26.

8 Umberson D. Black deaths matter: race, relationship loss, and effects on survivors. J Health Soc Behav 2017;58:405-20.

9 Umberson D, Olson JS, Crosnoe R, et al. Death of family members as an overlooked source of racial disadvantage in the United States. Proc Natl Acad Sci U S A 2017;114:915-20.

10 Martikainen P, Valkonen T. Mortality after the death of a spouse: rates and causes of death in a large Finnish cohort. Am J Public Health 1996;86:1087-93.

11 Elwert F, Christakis NA. The effect of widowhood on mortality by the causes of death of both spouses. Am J Public Health 2008;98:2092-8.

12 Li J, Precht DH, Mortensen PB, et al. Mortality in parents after death of a child in Denmark: a nationwide follow-up study. Lancet 2003;361:363-7.

13 Song J, Floyd FJ, Seltzer MM, et al. Long-Term effects of child death on parents' health related quality of life: a Dyadic analysis. Fam Relat 2010;59:269-82

14 Li J, Laursen TM, Precht DH, et al. Hospitalization for mental illness among parents after the death of a child. $N$ Engl J Med 2005;352:1190-6.

15 Stroebe M, Stroebe W, Abakoumkin G. The broken heart: suicidal ideation in bereavement. Am J Psychiatry 2005;162:2178-80.

16 Rostila M, Saarela J, Kawachi I. Mortality in parents following the death of a child: a nationwide follow-up study from Sweden. $J$ Epidemiol Community Health 2012;66:927-33.

17 Rostila M, Mäki N, Martikainen P. Does the death of a child influence parental use of psychotropic medication? A follow-up register study from Finland. PLoS One 2018;13:e0195500.

18 Finnäs F, Rostila M, Saarela J. Divorce and parity progression following the death of a child: a register-based study from Finland. Popul Stud 2018;72:41-51.

19 Levav I, Kohn R, Iscovich J, et al. Cancer incidence and survival following bereavement. Am J Public Health 2000;90:1601.

20 Sanders CM. A comparison of adult bereavement in the death of a spouse, child, and parent. Omega 1980;10:303-22.

21 Castle SE. The (Re)Negotiation of Illness Diagnoses and Responsibility for Child Death in Rural Mali. Med Anthropol Q 1994;8:314-35.

22 Dettwyler KA. Dancing skeletons: life and death in West Africa. Waveland Press, 2013.

23 Einarsdóttir J. Tired of weeping: mother love, child death, and poverty in Guinea-Bissau. Univ of Wisconsin Press, 2005.

24 Haws RA, Mashasi I, Mrisho M, et al. "These are not good things for other people to know": how rural Tanzanian women's experiences of pregnancy loss and early neonatal death may impact survey data quality. Soc Sci Med 2010;71:1764-72.

25 Weitzman A, Smith-Greenaway E. The marital implications of bereavement: child death and intimate partner violence in West and central Africa. Demography 2020;57:347-71.

26 Knodel J, Hermalin Al. Effects of birth RANK, maternal age, birth interval, and sibship size on infant and child mortality: evidence from 18th and 19th century reproductive histories. Am J Public Health 1984;74:1098-106.

27 Smith-Greenaway E, Alburez-Gutierrez D, Trinitapoli J, et al. Replication data for global burden of maternal bereavement: indicators of the cumulative prevalence of child loss.

28 Balayla J, Azoulay L, Abenhaim HA. Maternal marital status and the risk of stillbirth and infant death: a population-based cohort study on 40 million births in the United States. Womens Health Issues 2011;21:361-5

29 Sartorius BKD, Sartorius K. Global infant mortality trends and attributable determinants - an ecological study using data from 192 countries for the period 1990-2011. Popul Health Metr 2014:12:1-15.

30 World population prospects 2019, 2019. Available: https:// population.un.org/wpp/Download/Standard/Fertility/

31 Keyfitz N. Applied mathematical demography. Springer, 1985.

32 Goodman LA, Keyfitz N, Pullum TW. Family formation and the frequency of various kinship relationships. Theor Popul Biol 1974;5:1-27.

33 Wachter KW. Essential demographic methods. Harvard Univ. Press, 2014.

34 Preston SH, Heuveline P, Guillot M. Demography: measuring and modeling population processes. Blackwell Publishers, 2001.

35 Das Gupta M, clustering D. Death Clustering, Mothers' Education and the Determinants of Child Mortality in Rural Punjab, India. Popul Stud 1990;44:489-505.

36 Sastry N. Family-Level clustering of childhood mortality risk in northeast Brazil. Popul Stud 1997;51:245-61.

37 UN. World population prospects 2019: highlights (st/esa/ser. A/423), 2019.

38 GA U. Transforming our world: the 2030 agenda for sustainable development. New York, NY, USA: Division for Sustainable Development Goals, 2015

39 McNeil MJ, Namisango E, Hunt J, et al. Grief and bereavement in parents after the death of a child in low- and middle-income countries. Children 2020;7:39.

40 Bolton JM, Au W, Chateau D, et al. Bereavement after sibling death: a population-based longitudinal case-control study. World Psychiatry 2016;15:59-66.

41 Fletcher J, Mailick M, Song J, et al. A sibling death in the family: common and consequential. Demography 2013;50:803-26.

42 Fletcher J, Vidal-Fernandez M, Wolfe B. Dynamic and heterogeneous effects of sibling death on children's outcomes. Proc Natl Acad Sci U S A 2018;115:115-20.

43 Smith-Greenaway E, Weitzman A. Sibling mortality burden in low-income countries: a descriptive analysis of sibling death in Africa, Asia, and Latin America and the Caribbean. PLoS One 2020;15:e0236498.

44 Organization, W. H. Adverse childhood experiences international questionnaire: pilot study review and finalization meeting. Geneva, Swtizerland: World Health Organization, 2011.

45 Shakespeare C, Merriel A, Bakhbakhi D, et al. Parents' and healthcare professionals' experiences of care after stillbirth in low- and middle-income countries: a systematic review and metasummary. BJOG 2019;126:12-21.

46 Meyer AC, Opoku C, Gold KJ. "They Say I Should not Think About It:": A Qualitative Study Exploring the Experience of Infant Loss for Bereaved Mothers in Kumasi, Ghana. Omega 2018;77:267-79.

47 Goldstein RD, Lederman RI, Lichtenthal WG, et al. The grief of mothers after the sudden unexpected death of their infants. Pediatrics 2018;141:e20173651.

48 Büyüm AM, Kenney $C$, Koris $A$, et al. Decolonising global health: if not now, when? BMJ Glob Health 2020;5:e003394.

49 Montgomery L, Owen-Pugh V. Bereavement counselling in Uganda and Northern Ireland: a comparison. Br J Guid Counc 2018;46:91-103.

50 Scheper-Hughes N. Infant mortality and infant care: cultural and economic constraints on nurturing in northeast Brazil. Soc Sci Med 1984;19:535-46

51 Dorsey S, Lucid L, Martin P, et al. Effectiveness of task-shifted trauma-focused cognitive behavioral therapy for children who experienced parental death and posttraumatic stress in Kenya and Tanzania: a randomized clinical trial. JAMA Psychiatry 2020;77:464-73. 
52 Thurman TR, Luckett BG, Nice J, et al. Effect of a bereavement support group on female adolescents' psychological health: a randomised controlled trial in South Africa. Lancet Glob Health 2017;5:e604-14.

53 Stroebe M, Schut H. Bereavement in times of COVID-19: a review and theoretical framework. Omega 2021;82:500-22.

54 Verdery AM, Smith-Greenaway E, Margolis R, et al. Tracking the reach of COVID-19 kin loss with a bereavement multiplier applied to the United States. Proc Natl Acad Sci U S A 2020;117:17695-701.

55 Patel V, Prince M. Global mental health: a new global health field comes of age. JAMA 2010;303:1976-7.

56 Sankoh O, Sevalie S, Weston M. Mental health in Africa. Lancet Glob Health 2018;6:e954-5.

57 Herrman H, Kieling C, McGorry P, et al. Reducing the global burden of depression: a Lancet-World psychiatric association Commission. The Lancet 2019;393:e42-3.

58 Organization, W. H. Depression and other common mental disorders: global health estimates, 2017.

59 Shear MK. Grief and mourning gone awry: pathway and course of complicated grief. Dialogues Clin Neurosci 2012:14:119.

60 Shear MK. Complicated grief. N Engl J Med Overseas Ed 2015;372:153-60.

61 Kersting A, Brähler E, Glaesmer H, et al. Prevalence of complicated grief in a representative population-based sample. J Affect Disord 2011;131:339-43.

62 Killikelly C, Bauer S, Maercker A. The assessment of grief in refugees and post-conflict survivors: a narrative review of etic and emic research. Front Psychol 2018;9:1957.
63 Baschieri A, Gordeev VS, Akuze J, et al. "Every Newborn-INDEPTH" (EN-INDEPTH) study protocol for a randomised comparison of household survey modules for measuring stillbirths and neonatal deaths in five Health and Demographic Surveillance sites. J Glob Health 2019;9.

64 Helleringer S, Arhinful D, Abuaku B, et al. Using community-based reporting of vital events to monitor child mortality: lessons from rural Ghana. PLoS One 2018;13:e0192034.

65 Helleringer S, Liu L, Chu Y, et al. Biases in survey estimates of neonatal mortality: results from a validation study in urban areas of Guinea-Bissau. Demography 2020;57:1705-26.

66 Alkema L, Chou D, Hogan D, et al. Global, regional, and national levels and trends in maternal mortality between 1990 and 2015 with scenario-based projections to 2030: a systematic analysis by the un maternal mortality estimation Inter-Agency group. Lancet 2016;387:462-74.

67 Hogan MC, Foreman KJ, Naghavi M, et al. Maternal mortality for 181 countries, 1980-2008: a systematic analysis of progress towards millennium development goal 5. The Lancet 2010;375:1609-23.

68 Bongaarts J. Global trends in AIDS mortality. Popul Dev Rev 1996;22:21-45.

69 Lizcano Pabón LdelM, Moreno Fergusson ME, Palacios AM, Pabón L, del ML, Fergusson MEM. Experience of Perinatal Death From the Father's Perspective. Nurs Res 2019;68:E1-9.

70 Roberts L, Montgomery S, Ganesh G, et al. Addressing stillbirth in India must include men. Issues Ment Health Nurs 2017;38:590-9.

71 Pradhan M, Sahn DE, Younger SD. Decomposing World health inequality. J Health Econ 2003;22:271-93. 